\section{Collapse of ta \\ [LONDON] Nine days of talks on a global pro- tocol to regulate international trade in genet- ically modified organisms (GMOs) broke down last week, even though at one point agreement appeared within sight. Negotia- tions are not expected to resume before the next conference of the parties to the United Nations biodiversity convention in May 2000 at Nairobi. \\ The main reason for failure appears to have been the insistence by grain-exporting countries - led by the United States and known as the Miami group - that countries be allowed to export genetically modified commodities such as food, pharmaceuticals and animal feed without seeking permission

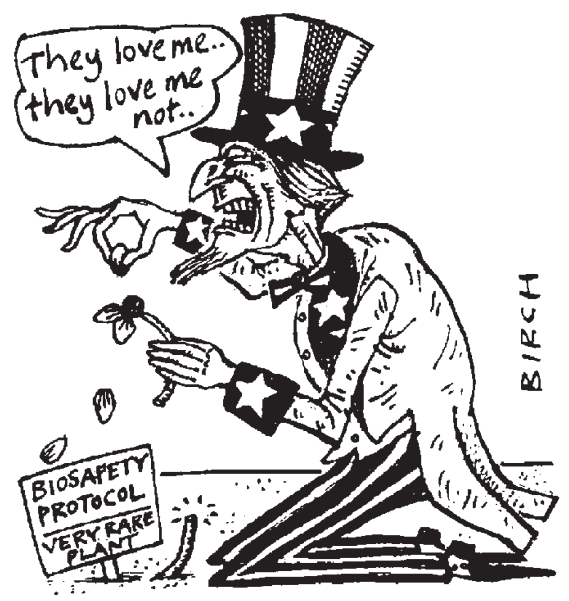
from an importing country.

The Miami group was also keen that the protocol should not conflict with existing international trade agreements. In contrast, European Union (EU) member states, most developing countries present, and environmental groups, wanted the protocol to be an independent legal instrument.

Developing countries also wanted the socioeconomic impacts of GMOs to be taken into account during any assessment of their environmental risks, as well as provision in the protocol for compensation in the event of accidents involving the transport of GMOs.

Earlier during the talks, agreement had appeared close when the chair, Veit Koester, director of the National Forests Agency of Denmark, produced a compromise text for a protocol satisfying these demands.

The compromise text also satisfied the Miami group's demands that only genetically modified organisms - and not commodities - would need permission before being shipped to an importing country.

Developing countries, the EU states and the Miami group appeared poised to agree on a later version of this text, which included the possibility of some genetically modified commodities being subject to import permission. But the talks collapsed when the Miami group refused to budge on the article specifying that the protocol should not conflict with existing international trade agreements.

Some delegates have suggested that progress in the talks may have been hindered by the predominance of scientists among the delegates from smaller countries, for example from Africa, with little experience in international negotiations.

But Sateeaved Seebaluck of the Ministry of Local Government of Mauritius says that, although smaller countries were unable to field the full range of expertise, the emergence of the African group as a single block has changed this. "Now we have access to as many scientists, lawyers and diplomats as we need."

The lack of agreement has intensified an increasingly significant conflict between trade and environmental concerns. A future agreement will be a key test of the UN biodiversity convention, which is seen by its supporters as the only international agreement in which environmental protection is given the same importance as trade.

According to Kimo Goree, managing editor of the Earth Negotiations Bulletin, "the protocol could prove to be the convention's saving grace, or a nail in its coffin as resolution of such trade issues will be key to its final role". The bulletin was the only publication allowed access to closed negotiation sessions.

But the lack of agreement still seems to have satisfied both sides, at least for the time being. Representatives of industry left the meeting in Cartagena, Colombia, happier than when they arrived. They have always favoured international guidelines on trade in GMOs, as opposed to a legally binding protocol, which they consider would be harmful to trade.

The lack of agreement also represents the first major success of industry's more conciliatory approach to international environmental negotiations, which in the past has been much more confrontational.

Unlike at the climate change negotiations that resulted in the Kyoto protocol in 1997, industry played an active role in biosafety preparatory meetings, and had a much closer relationship with key governments, including the United States.

Despite losing the support of Argentina, Chile and Uruguay to the Miami group, but gaining the support of South Africa, developing countries and environmental groups, on the whole, are not displeased with the outcome. Many of them felt that they were better off not signing what they privately considered to be a weak agreement.

Ehsan Masood

\title{
NASA plans two-stage Hubble repair to keep the data flow ing
}

[WASHINGTON] The US space agency NASA may repair the Hubble Space Telescope earlier than scheduled, to prevent a failure in its guidance system that would temporarily halt scientific observations.

If the plan goes ahead, an astronaut crew will replace the telescope's gyroscopes in October, rather than waiting until the planned 'servicing mission' in June next year.

The same crew would then return a year later to install a new scientific camera and to perform other repairs scheduled for the June 2000 mission. An emergency rescue is needed following the partial failure in January of one of the telescope's six gyroscopes, which keep it orientated in space. Hubble needs three gyroscopes to function normally, with the rest as backups.

But, with two having already failed completely, an electrical malfunction caused a third gyro to behave erratically, and it was shut down by engineers at NASA's Goddard Space Flight Center in Maryland.

According to David Leckrone, the Hubble project scientist at Goddard, there is no way to predict when a similar failure might occur in another gyro. A fourth loss would automatically put Hubble into a 'safe' mode, where it would remain protected but stop observations.

Hubble managers endorse the October mission, but NASA's space shuttle and science offices have yet to agree to the plan.

Delays with the Russian 'service module' have left shuttle managers juggling their launch schedule. The module was to have been delivered to the space station in September, but now may not fly until
November or later. These Russian schedule slips left the shuttle with no mission this autumn, allowing the Hubble rescue.

NASA science managers have a different concern. Splitting the repair mission would give twice the opportunity to damage or contaminate the telescope.

But, says Leckrone, the planned June 2000 repair, which will install an Advance Camera for Surveys and cryogenic cooling system, and update computers, "was shaping up to be quite complex," with six space walks. Spreading the work over two missions makes it more manageable, he says.

NASA administrator Daniel Goldin told a congressional committee last week that NASA wants to decide soon. Leckrone says it may be a "couple of weeks" before the agency can commit to the plan.
Tony Reic hhardt 